\title{
Accurate rotor speed estimation for low-power wind
}

\section{turbines}

\author{
Juan M. Guerrero*, Carlos Lumbreras, David Reigosa, Daniel Fernandez, Fernando Briz, Cristian Blanco \\ Department of Electrical Engineering, University of Oviedo \\ Email*: guerrero@uniovi.es
}

\begin{abstract}
Small grid-tied wind turbines based on permanent magnet generators often use a cost-effective power converter topology consisting of a passive rectifier, a boost converter, and an H-bridge inverter. Speed or position sensors are rarely used due to cost issues. Model-based estimators relying on electrical magnitudes are used instead. However, such estimators are parameter sensitive, which limit their accuracy. Further concerns arise if these parameters change with the operating condition of the machine, mainly due to temperature. Speed sensorless control using the rectifier voltage ripple is analyzed in this paper. This technique provides good dynamic response and does not depend on machine parameters. Simulations are provided for speed and power tracking comparison with an accurate modelbased speed estimation method operating at non-rated parameters. They show the speed accuracy and power tracking capability of the proposed method are similar to that provided by a speed sensor. This is translated into a $0.9 \%$ power increase when the model-based speed estimator shows $9 \%$ of error. Experimental results are carried out to test the effect of current and temperature in the estimation, showing temperature insensitivity and some distortion due to fast current transients. A speed estimation accuracy of zero mean error and $1.7 \%$ standard error is experimentally obtained in the regular operation of the wind turbine.
\end{abstract}

\section{INTRODUCTION}

In the last years, cost and sustainability concerns have raised the interest in the use of low-power renewable resources for self-generation due to cost issues. Small wind turbines are good candidates to satisfy this increasing demand in farms, homes and small businesses [1]. Diverse electrical machine types and power converter topologies can be used in these applications. In the low power segment $(<5 \mathrm{~kW})$, permanent magnet generators are preferred due to their efficiency and system simplicity [2], [3]. Several power converter topologies have been proposed for the wind generator side, including passive rectifier without or with DC converter (buck, boost, SEPIC, ...), half of full controlled rectifiers, etc. Passive rectifier followed by a DC/DC converter is especially appealing due to its simplicity and cost [2]-[4] and will be used in this work.

Below rated wind speed, wind turbines are operated using a maximum power point tracking (MPPT) strategy. Tipspeed ratio (TSR) control, maximum power vs. rotor speed look-up tables, or perturb and observe methods (P\&O) 
can be used for MPPT. P\&O methods [5]-[8] are quite independent on the machine parameters but show a relatively slow convergence. The MPPT tracking can be speeded up by using predefined turbine/generator models or look-up tables providing an optimum rotor speed or generator voltage reference based on the measured electrical power [9]-[13]. Unfortunately, the optimum relationship given by the model only holds at ideal (i.e. rated parameters) conditions.

At high wind speeds, the torque produced by the blades exceeds the maximum braking torque that can be produced by the generator. Disk brakes, pitch control, stall control, yaw control, or electrical braking are methods available to stop the turbine in case of power excess [14]. Soft-stall methods have been also proposed to keep the turbine generating at a non-optimum point in the event of power or torque excess [6], [7], [9]-[12].

Both model-based MPPT and implementation of turbine power/torque limit strategies require direct or indirect knowledge of the turbine speed. However, shaft speed sensors are rarely used in low-power applications due to cost, meaning that speed must be estimated or indirectly controlled from available electrical variables.

The rotor speed is often indirectly adjusted by controlling the rectifier DC voltage [11]-[13]. The main problem of this type of controllers is the strong decoupling between the rotor speed and the rectifier voltage during high loads (i.e. high wind speed conditions). This may easily lead to unstable behavior and makes soft-stall implementation difficult. Rotor speed estimation only using the DC magnitude of the rectifier output voltage has also been proposed [6], [9]. The rotor speed estimation enables the estimation of the turbine mechanical torque, easing the soft-stall implementation. However, neglecting the load current effect in the rotor speed estimation results in large rotor speed estimation errors at high loads. An accurate speed estimation model using both the rectifier DC voltage magnitude and the boost converter current was proposed in [10]. Soft-stall is implemented through a mechanical torque observer using the speed estimate as input. Despite the improved accuracy, this method is also sensitive to machine parameter variation.

Methods using a different set of sensors have also been proposed for this power converter topology. A sensorless sliding-mode controller is proposed in [15]. The speed is estimated from the phase voltages and currents. However, the extra voltage and current sensors penalize cost. In addition, the speed estimation is also obtained using a parameter-dependent machine model. Measurement of a phase voltage of the generator was proposed in [16], rotor frequency being obtained from phase voltage frequency. An open-loop feed-forward controller is then used to operate the boost converter. However, operation at low load levels and the phase voltage frequency extraction was not discussed in that work. Besides, the lack of a current controller decreases the system dynamic response and makes the use of soft-stall techniques unfeasible. Furthermore, the method requires a constant output DC-link voltage, not being therefore suitable for single-phase grid connection.

A method for rotor speed estimation using the rectifier DC voltage ripple is proposed [17]. The frequency of the 
voltage ripple components is a function of the generator speed and does not depend on machine parameters or load conditions. Simulations show the method promising to enable proper MPPT tracking and high wind speed turbine protection of small wind turbines under different operating or environmental conditions. However, the major concern for its use is the signal-to-noise ratio due to the different magnitude of the voltage fundamental component and the ripple components. This paper explains the physical principle and conditions of the signal tracked for rotor speed estimation; analyzes the method accuracy both for speed and turbine torque estimation (used for soft-stall) and its impact on the harvested power; clarifies implementation issues; experimentally demonstrates the method feasibility in actual conditions including fast current change, temperature change and regular operation of the turbine; and experimentally quantifies the estimation errors.

\section{SYSTEM DESCRIPTION}

Fig. 1 shows a schematic representation of the generation system. It comprises a wind turbine, permanent magnet synchronous generator (PMG), passive rectifier, boost converter, H-bridge inverter and line filter for grid connection. The variables measured for control purposes are the rectifier output voltage, $v_{r}$, boost current, $i_{b}$, DC-link voltage, $v_{d c}$, grid current, $i_{g}$, and grid voltage $v_{g}$, as shown in Fig. 1. Parameters of turbine and generator used for simulation as well as for experimental verification can be found in Tables I and II. The relevant boost converter parameters are shown in Table III.

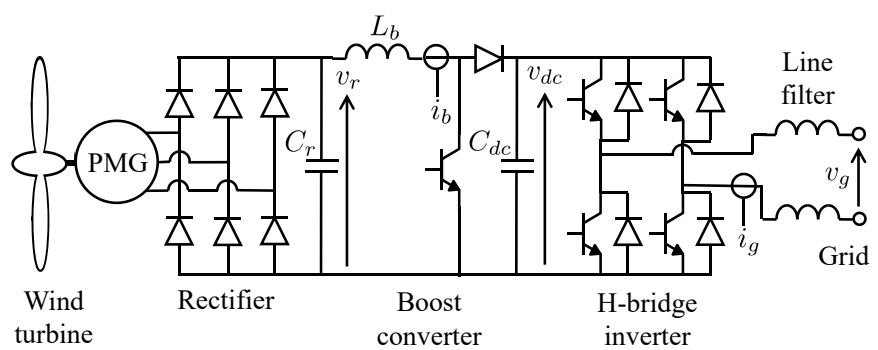

Fig. 1. Schematic diagram of the wind generating system [17].

TABLE I

TURBINE PARAMETERS

\begin{tabular}{lcc}
\hline \hline Rated power output & $P_{t_{-} \text {rated }}$ & $1.2 \mathrm{~kW}$ \\
Rated wind speed & $v_{w_{-} \text {rated }}$ & $12 \mathrm{~m} / \mathrm{s}$ \\
Rated rotor speed & $\omega_{r m_{-} \text {rated }}$ & $600 \mathrm{r} / \mathrm{min}$ \\
Turbine radius & $R$ & $0.875 \mathrm{~m}$ \\
Mechanical inertia & $J_{t}$ & $0.74 \mathrm{~kg} \cdot \mathrm{m}^{2}$ \\
Optimal TSR & $\lambda_{\max }$ & 4.6 \\
Optimal power coeffcient & $c_{p_{-} \max }$ & 0.47 \\
\hline \hline
\end{tabular}

The turbine control strategy followed in this paper is described in [10]. The turbine speed is controlled to follow the command provided by the MPPT algorithm. Under high wind speeds, the turbine speed command is decreased 
TABLE II

GENERATOR PARAMETERS

\begin{tabular}{lcc}
\hline \hline Rated power & $P_{g_{-} \text {rated }}$ & $1.7 \mathrm{~kW}$ \\
Rated speed & $\omega_{r m_{-} \text {rated }}$ & $500 \mathrm{r} / \mathrm{min}$ \\
Rated current & $i_{r}$ & $3.7 \mathrm{~A}$ \\
Stator resistance & $r_{s}$ & $6.03 \Omega$ \\
Inductance & $L_{d}=L_{q}$ & $63 \mathrm{mH}$ \\
Back-emf constant & $k_{e}$ & $1.188 \mathrm{~V}_{\text {peak }} / \mathrm{r} / \mathrm{min}$ \\
Pole number & $p$ & 12 \\
Inertia constant & $J_{g}$ & $.00581 \mathrm{~kg} \mathrm{~m}^{2}$ \\
\hline \hline
\end{tabular}

TABLE III

BOOST CONVERTER PARAMETERS

\begin{tabular}{lcc}
\hline \hline Input capacitance & $C_{r}$ & $273 \mu \mathrm{F}$ \\
Boost inductance & $L_{b}$ & $1.2 \mathrm{mH}$ \\
DC-link capacitance & $C_{d c}$ & $273 \mu \mathrm{F}$ \\
\hline
\end{tabular}

to avoid surpassing the generator rated torque. It must be remarked the rotor speed estimation method proposed here can be used with any other control strategy proposed in the literature.

The no-load output voltage of a three-phase diode rectifier supplied by a three-phase generator consists of a DC component and harmonics (voltage ripple) at integer multiples of six times the AC voltage frequency (1) [18], where $V_{g}$ is the amplitude of the generator output voltage, $\omega_{r}$ is the three-phase generator voltage frequency and $n$ is the harmonic number. It is noted that $V_{g}$ in (1) can contain additional harmonic components due to the non-ideal construction (i.e. asymmetries, tolerances, etc.) of the generator.

$$
v_{r}=\frac{3 \sqrt{3}}{\pi} V_{g}\left(1-\sum_{n=1}^{\infty} \frac{2}{(6 n)^{2}-1} \cos \left(6 n \omega_{r} t\right)\right)
$$

Generator speed can be indirectly controlled by regulating the DC component [11]-[13]; it can also be directly controlled by estimating the rotor speed from that DC component [6], [9]; or from the ripple present in the rectifier output voltage [17]. The DC component depends on the back-emf voltage, which is a function of speed; it is also dependent on the load, due to the voltage drop in stator windings. Therefore, compensation of the voltage drop in the stator windings is required for improved estimation accuracy. The measured load (i.e. boost converter) current can be used for this purpose. The rotor speed is accurately estimated using a polynomial approximation function using boost current and rectifier voltage (2) in [10]. Coefficients of this function are obtained in a commissioning stage and stored in a table, which is later accessed during normal operation of the turbine.

$$
\hat{\omega}_{r m}\left(v_{r}, i_{b}\right)=a_{00}+a_{10} v_{r}+a_{01} i_{b}+a_{11} v_{r} i_{b}+a_{02} i_{b}^{2}+a_{12} v_{r} i_{b}^{2}+a_{03} i_{b}^{3}
$$


where $a_{i j}$ are the polynomial coefficients obtained during the commissioning process.

The polynomial coefficients depend on the generator stator phase resistance and inductance, and on the back-emf constant. Provided these parameters are temperature dependent, the estimation accuracy of (2) will also depend on the generator operating temperature.

Instead of the DC component, the rectifier output voltage ripple can be used for speed estimation purposes. Since the frequency of voltage ripple harmonics is a function of rotor speed exclusively and is not affected by machine parameters or load level, a robust rotor speed estimation is possible in this case.

Equation (1) assumes no capacitor is connected at the rectifier output. The boost converter input capacitor, $C_{r}$, seen in Fig. 1 attenuates all the AC components of the rectifier voltage, including those useful for rotor speed estimation. However, they are not completely removed due to the low value of the capacitor. Elimination of the capacitor has also been proposed to either improving the power factor, decrease the torque ripple, or simply due to cost reasons [13]. The proposed method has shown a good behavior with a capacitance up to $300 \mu \mathrm{F}$, which is relatively high for the system power rating.

Fig. 2 shows the frequency spectrum of the rectifier voltage for a constant generator rotor speed of $300 \mathrm{r} / \mathrm{min}$ (5 $\mathrm{Hz}$ ) and different load levels. The first harmonic in (1) at $6 \omega_{r}$ is readily visible in all cases. Even if observable, the magnitude of the second harmonic at $12 \omega_{r}$ is significantly smaller, and consequently difficult to track. It is also observed that the magnitude of both the first and second harmonics is significantly affected by the load level. Finally, several harmonic components at relatively low frequencies are observed in Fig. 2, mainly due to machine constructive asymmetries. While some of these harmonics also occur at frequencies which are multiples of the rotor speed, their spectral proximity and the fact that are produced by undesired asymmetries make inadvisable their use for rotor speed estimation.

Estimation of the rotor speed using the first harmonic component (3) of the rectifier voltage is discussed in the following section. For the sake of readability, this component will be denoted as $\tilde{v}_{r}$ hereafter.

$$
\omega_{n 1}=6 \cdot \omega_{r}=6 \cdot \frac{p}{2} \cdot \omega_{r m}
$$

where $\omega_{n 1}$ is the frequency of the first harmonic component, $p$ is the pole number and $\omega_{r m}$ is the mechanical rotor speed.

\section{SPEed ESTIMATION USING THE RECTIFIER OUTPUT VOLTAGE RIPPLE}

The signal processing used to isolate $\tilde{v}_{r}$ from the overall DC link voltage and obtain the rotor speed can be seen in the block diagram in Fig. 3. An adaptive band-pass filter (BPF) extracts the ripple component containing speed information from the rectifier voltage $v_{r}$. The amplitude of this component also depends on rotor speed; 


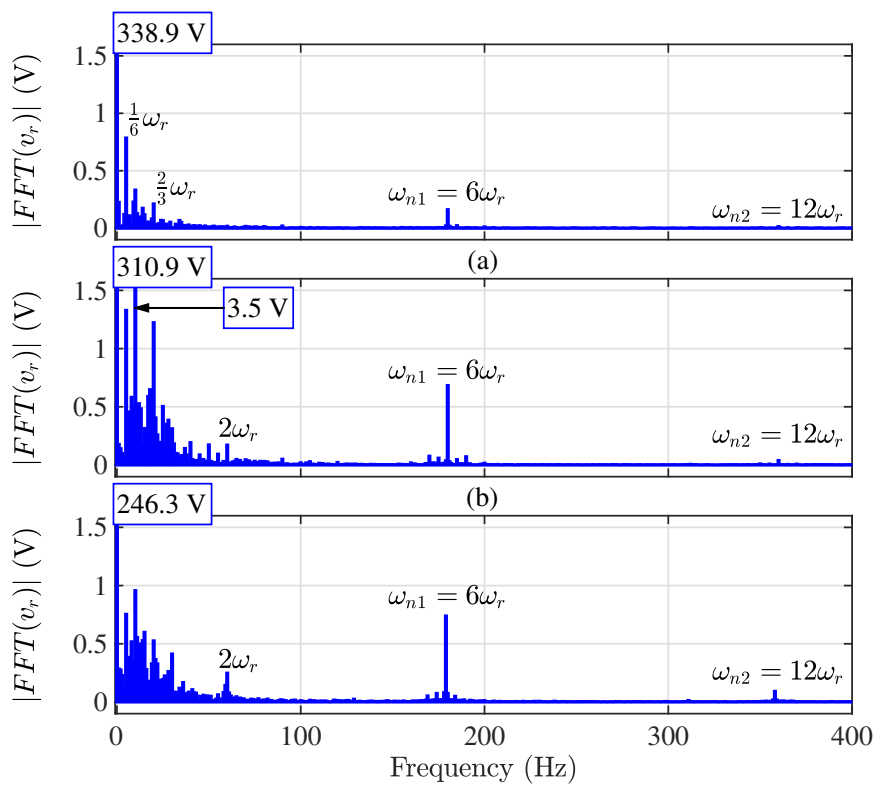

(c)

Fig. 2. Experimental results. Rectifier output voltage frequency spectrum for a constant rotor speed of $300 \mathrm{r} / \mathrm{min}(5 \mathrm{~Hz})$ and three boost current levels: (a) $i_{b}=0 \mathrm{~A}$; (b) $i_{b}=1 \mathrm{~A}$; (c) $i_{b}=3.7 \mathrm{~A}$ (rated). Magnitude is indicated for those components larger than the y-axis scale. The rotor speed is controlled by the load drive.

a peak detector is used for normalization. The frequency of the resulting component, $\tilde{v}_{r_{-} n}$, is obtained with a complex vector phase-lock loop (PLL), where the quadrature component $\tilde{v}_{r_{-} \beta}$ is obtained with an all-pass filter (APF). Finally, the ripple component frequency $\hat{\omega}_{n 1}$ is scaled to the rotor speed $\hat{\omega}_{r m}$ using (3). The performance of each processing stage is analyzed in section V. Further details on the implemented blocks can be found in [17]. However, some additional comments are made below regarding some blocks due to their importance for a correct implementation.

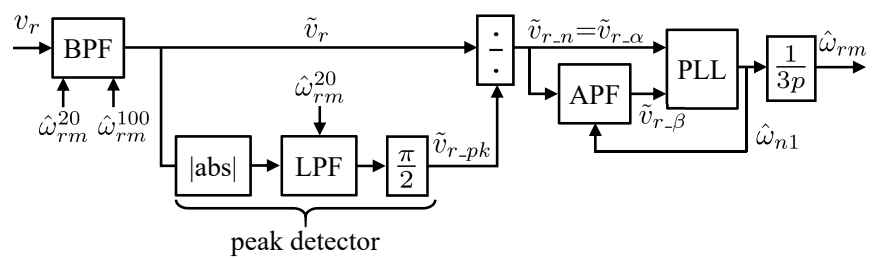

Fig. 3. Block diagram of the rotor speed estimator.

\section{A. Adaptive band-pass filter}

The BPF design is challenging due to several reasons, including:

- the large range of variation $(0-420 \mathrm{~Hz})$ of the voltage ripple frequency, which is a consequence of the large range of variation of generator speed $(0-700 \mathrm{r} / \mathrm{min})$.

- presence of spurious frequency components in the rectifier at frequencies nearby $\tilde{v}_{r}$ (i.e. at $\frac{1}{3} \omega_{n 1}$ and $2 \omega_{n 1}$ ). 
- the low resolution of the analog-to-digital (AD) converter capturing the voltage ripple, as it is scaled for the DC component, which is significantly larger (see Fig. 2).

- transients in the DC component of the rectifier output voltage, which can produce additional frequency components and interfere with the method.

A fourth-order speed adaptive Butterworth type BPF implemented by cascading two pairs of second-order adaptive high-pass and low-pass filters has been designed. It ensures a good attenuation of the undesired components while adapts the passband to the rotor speed. The resulting BPF frequency response can be seen in Fig. 4.

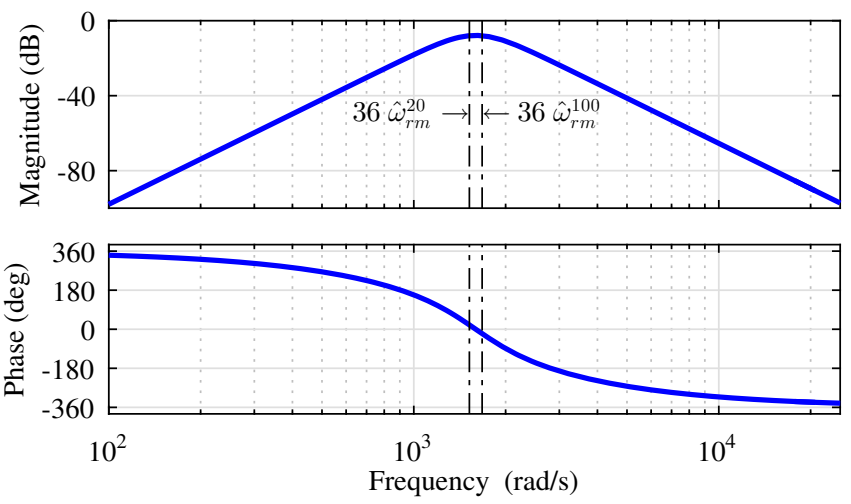

Fig. 4. Band-pass filter Bode diagram when $\hat{\omega}_{r m}^{20}=403 \mathrm{r} / \mathrm{min}$ and $\hat{\omega}_{r m}^{100}=440 \mathrm{r} / \mathrm{min}$

Actual rotor speed will be bounded by the speed estimates provided by (2) at the lower and higher operating temperatures considered for this generator, which are 20 and $100{ }^{\circ} \mathrm{C}$ respectively. Due to this, cut-off frequencies $\hat{\omega}_{r m}^{100}$ and $\hat{\omega}_{r m}^{20}$ used by the adaptive band-pass filter are obtained using the polynomial function in (2). The coefficients are adjusted for the cases the generator operates at temperatures of 20 and $100{ }^{\circ} \mathrm{C}$. It must be remarked that inaccuracies in these estimates do not significantly affect the performance of the proposed method. Therefore, these estimates can be obtained by any other magnitude-based speed estimation method.

\section{B. Peak detector}

In a three-phase PLL, the $\beta$-axis (or $q$-axis) component is used as error signal, while the $\alpha$-axis (or $d$-axis) is often used for signal normalization. In the present application, the small magnitude of $\tilde{v}_{r}$ prevents from correct operation of such normalization. A peak detector mimicking the behavior of a passive rectifier is used instead.

\section{Simulation Results}

The dynamic performance of the proposed method has been first tested by means of simulation. Matlab/Simulink software has been used to model the system in Fig. 1, main design parameters can be found in Tables I, II and III. Controllers and estimation blocks discussed in previous sections have been discretized using bilinear (Tustin) approximation with a sampling frequency of $20 \mathrm{kHz}$, which is also the switching frequency of the boost converter. 


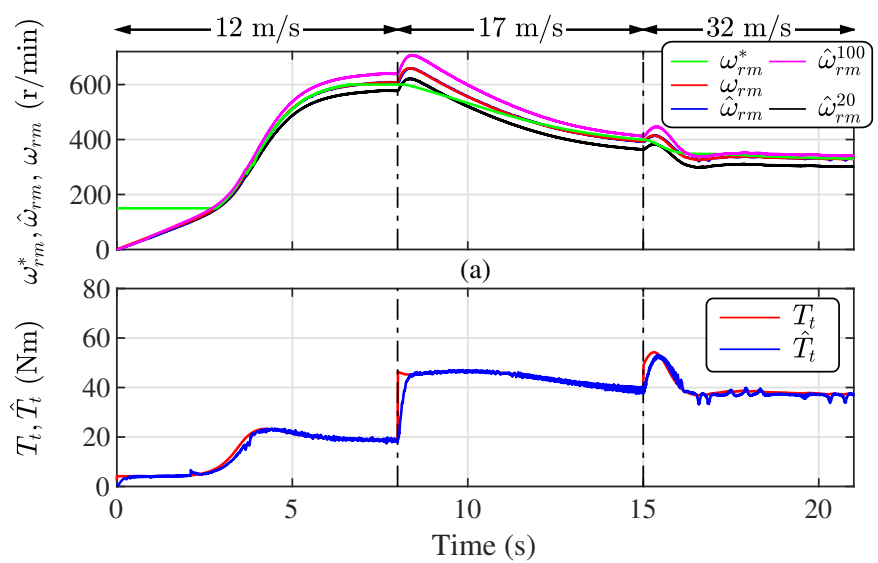

(b)

Fig. 5. Simulation results. Response of the proposed speed estimation method for wind speeds of $12 \mathrm{~m} / \mathrm{s}, 17 \mathrm{~m} / \mathrm{s}$ and $32 \mathrm{~m} / \mathrm{s}$, for a generator temperature of $60{ }^{\circ} \mathrm{C}$. (a) Speed command $\omega_{r m}^{*}$, rotor speed $\omega_{r m}$, estimated speed $\hat{\omega}_{r m}$, and model-estimated rotor speeds $\hat{\omega}_{r m}^{20}$ and $\hat{\omega}_{r m}^{100}$; (b) Actual $\left(T_{t}\right)$ and estimated $\left(\hat{T}_{t}\right)$ turbine torque.

The simulation model also includes antialiasing filters tuned for a $2.5 \mathrm{kHz}$ bandwidth and 12-bit analog-to-digital converters as in the experimental setup. The simulation uses a variable-step solver.

The behavior of the proposed method is shown in Fig. 5. Speed command $\omega_{r m}^{*}$ in Fig. 5(a) is obtained from the electrical power using the control strategy described in [10]. An operating temperature of $60{ }^{\circ} \mathrm{C}$ is considered in the generator. This produces a mismatch of $+16 \%$ in the stator resistance and $-4 \%$ in the magnet flux between the model and the actual machine. Fig. 5 shows the system behavior for three different wind speeds.

Good agreement between actual and estimated speeds is observed in Fig. 5(a). The model-based estimated speeds used as inputs for the adaptive filter, $\hat{\omega}_{r m}^{20}$ and $\hat{\omega}_{r m}^{100}$, are shown for reference. Fig. 5(b) shows the actual torque and the estimated torque used for the turbine protection at high wind speeds. Good agreement between actual and estimated values is also noticed, which is critical for turbine protection under high wind speeds.

Fig 6 shows the response of the model-based speed estimation method for the same parameter mismatch as in Fig. 5. While the rotor speed estimate $\hat{\omega}_{r m}^{20}$ used for speed feedback correctly follows the speed reference $\omega_{r m}^{*}$, there is a noticeable error between commanded and actual speeds [see Fig 6(a)], which also impacts the accuracy of the estimated turbine torque [see Fig. 6(b)]. Errors in the estimated speed and torque will affect both to turbine efficiency as well as protection under high wind speed.

Fig. 7 summarizes rotor speed and turbine torque estimation errors for ripple-based and model-based methods. Model-based estimation errors when the turbine operates at $20^{\circ} \mathrm{C}$ are also provided for reference. Degradation of model-based method performance at high temperature due to parameter mismatch is evident from the figure. On the contrary, the proposed ripple-based method is seen to provide accurate estimates of speed and turbine torque even in the case of large parameter mismatch, with the only exception of very low speed region. However, this is not relevant for the application as the turbine only operates in this region at start-up. 


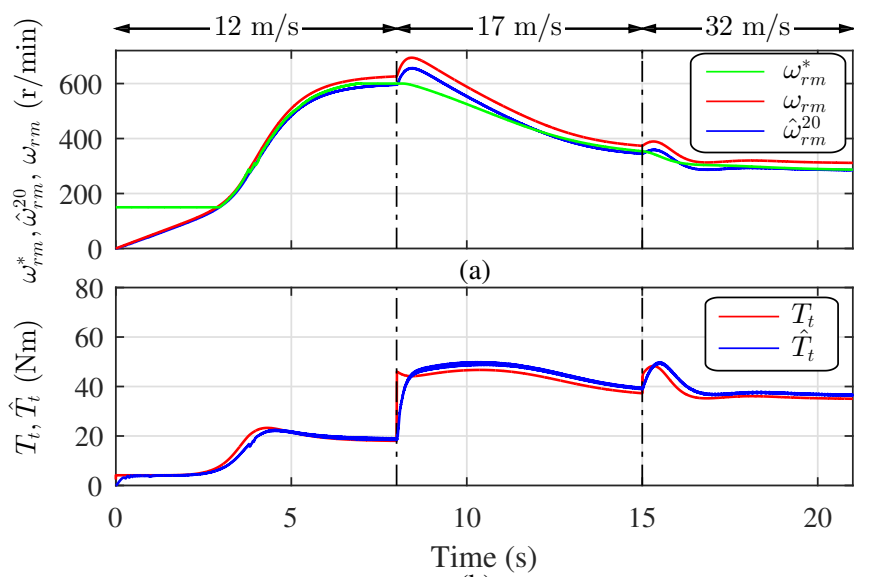

(b)

Fig. 6. Simulation results. Speed control and turbine torque estimation performance using a model-based speed estimation under unrated parameter conditions $\left(60{ }^{\circ} \mathrm{C}: 1.16 r_{s}, 0.96 k_{e}\right)$ and increasing wind conditions $(12 \mathrm{~m} / \mathrm{s}, 17 \mathrm{~m} / \mathrm{s}$ and $32 \mathrm{~m} / \mathrm{s})$ : (a) Rotor speed command, $\omega_{r m}^{*}$, rotor speed, $\omega_{r m}$, and model-estimated rotor speed, $\hat{\omega}_{r m}^{20}$; (b) Turbine torque, $T_{t}$, and estimated turbine torque $\hat{T}_{t}$.
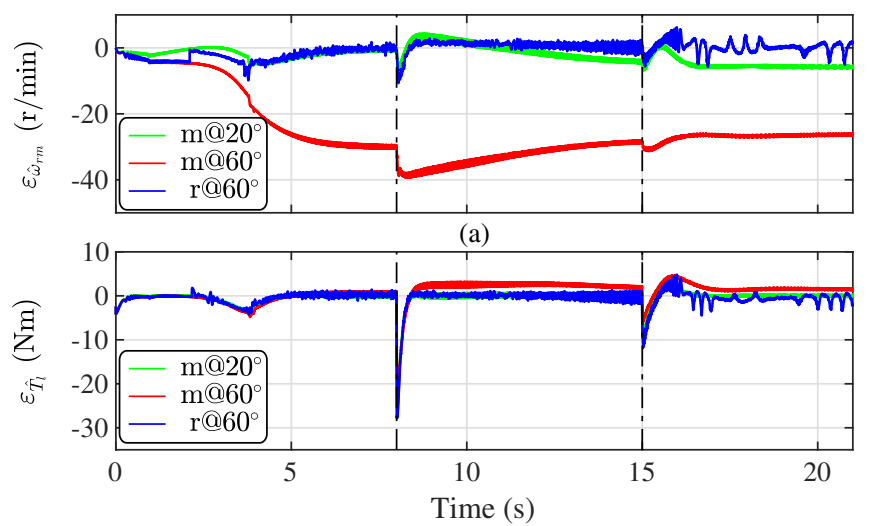

(b)

Fig. 7. Simulation results. (a) Rotor speed estimation error; (b) Turbine torque estimation error. Ripple-based method at $60{ }^{\circ} \mathrm{C}\left(\mathrm{r} @ 60^{\circ}\right.$,

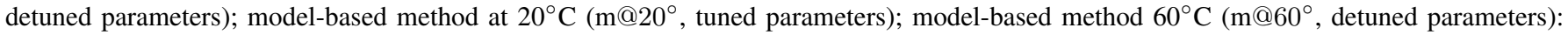

\section{A. Impact of speed estimation error on turbine efficiency}

A relevant issue is the impact of speed estimation errors on turbine efficiency. Knowing the turbine power coefficient versus tip-speed ratio curve, it is not difficult to obtain the power coefficient decrease in terms of the rotor speed estimation error, as shown in Fig. 8. This figure assumes the wind speed is perfectly known and the speed estimate is set to achieve the optimal tip-speed ratio to obtain the maximum power coefficient. Fig. 8 shows that the turbine used in this study is quite tolerant to speed estimation errors. For instance, a $-9 \%$ speed estimation error only brings a reduction of $1 \%$ in the maximum power coefficient (i.e. power harvested). Depending on the turbine design, the speed accuracy may have a higher impact in the power coefficient.

However, in most low-power wind turbines the wind speed is not measured. The MPPT trajectory is programmed as a look-up table in the turbine control system using the power vs. rotor speed characteristic of the turbine/generator system, as seen in Fig. 9. The system calculates the extracted power $P_{e}$ from the measured rectifier voltage $v_{r}$ 


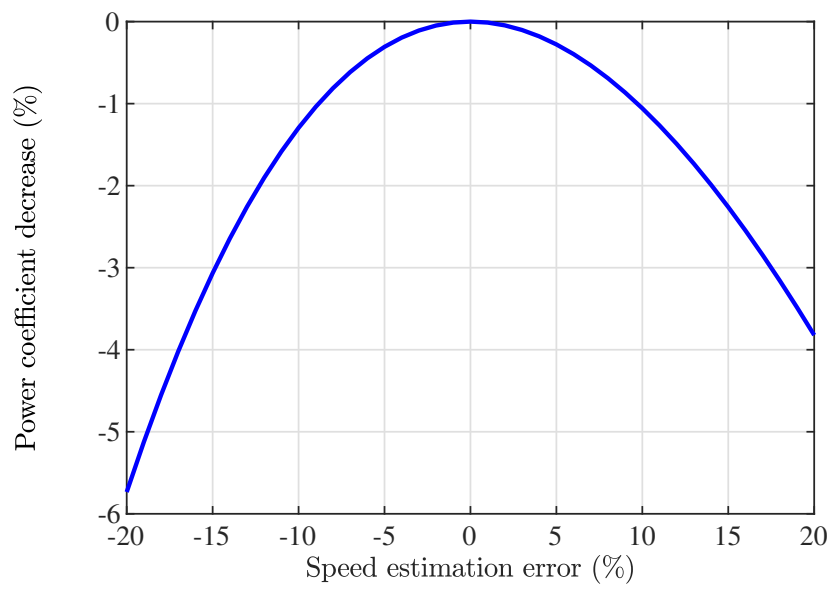

Fig. 8. Turbine power coefficient reduction in terms of the speed estimation error

and boost current $i_{b}$, from which speed reference $\omega_{m p p t o}^{*}$ for MPPT is obtained (see Fig. 9). Parameter mismatch e.g. due to temperature will shift the MPPT trajectory (red dotted line in Fig.9) and consequently the ideal MPPT speed reference. However, due to the flatness of the power/speed curves in the peak neighborhood, this difference is small in the turbine under study and has not been compensated.

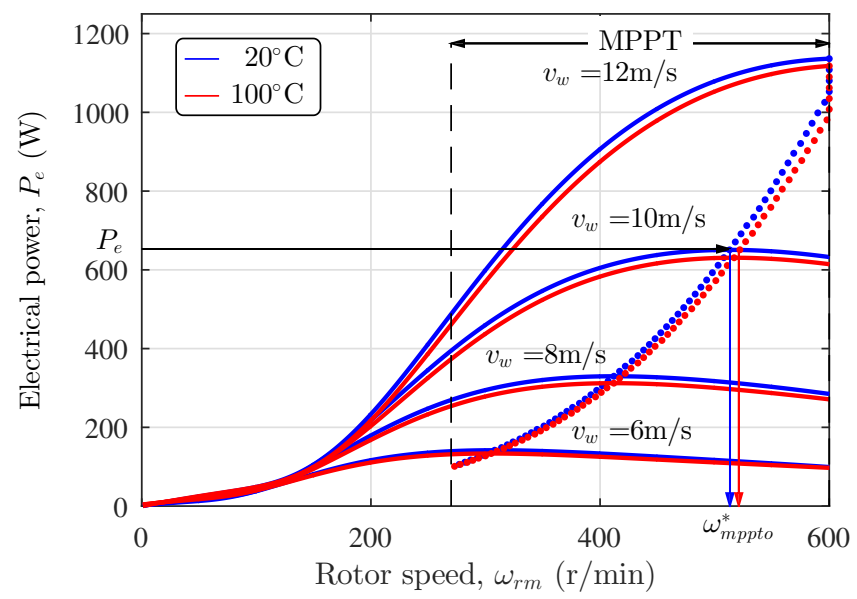

Fig. 9. Simulation results. Power vs. rotor speed characteristic of the turbine/generator (solid) and MPPT trajectory (dotted) for two different temperatures of $20^{\circ} \mathrm{C}$ and $100^{\circ} \mathrm{C}$ [17].

Fig 10(a) shows the generated power during wind speed transients, while Fig. 10(b) shows the difference between the power obtained using a speed sensor and the power acquired by both methods (4) when the generator is operating at a temperature of $100{ }^{\circ} \mathrm{C}$.

$$
\Delta P_{e}=P_{e_{-} \text {sensor }}-P_{e_{-} \text {sensorless }}
$$

According to Fig. 10(b) the proposed method provides a power increase in steady-state, which becomes more relevant at high wind speeds. The power obtained by both methods and the power difference at different wind speeds is summarized in Table IV. The obtained results are in agreement with Figs. 8 and 9. The operating temperature 

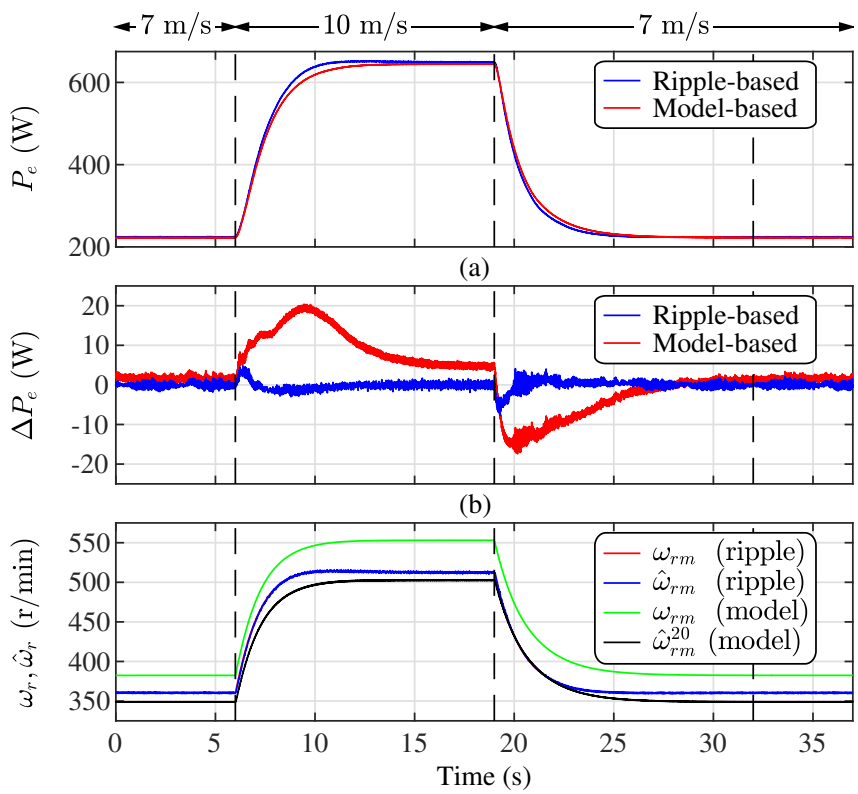

(c)

Fig. 10. Simulation results. Energy extraction comparison between the proposed and model-based methods with an operating temperature of $100{ }^{\circ} \mathrm{C}$ and changing wind speed (shown on top of figure). (a) Extracted power; (b) Power difference between sensorless and sensor operation. (c) Actual and estimated rotor speed. Note: (a) and (b) do not show the sensor-controlled case since overlaps the ripple-based case at this scale.

introduces a speed error in the model-based estimate of around $-9 \%$ as can be seen in Fig. 10(c). This corresponds to $-1 \%$ in the harvested power according to Fig. 8. However, the temperature rise also displaces the MPPT trajectory to the right, as seen in Fig. 9, compensating to some extent for the model-based speed underestimation.

TABLE IV

POWER ACQUIRED AT DIFFERENT WIND SPEEDS USING SENSOR OR ESTIMATORS

\begin{tabular}{c|ccccc} 
Wind speed $(\mathrm{m} / \mathrm{s})$ & 7 & 8 & 9 & 10 & 11 \\
\hline \hline Sensor & $224 \mathrm{~W}$ & $334 \mathrm{~W}$ & $475 \mathrm{~W}$ & $650 \mathrm{~W}$ & $864 \mathrm{~W}$ \\
Ripple & $224 \mathrm{~W}$ & $334 \mathrm{~W}$ & $475 \mathrm{~W}$ & $650 \mathrm{~W}$ & $864 \mathrm{~W}$ \\
Model & $222 \mathrm{~W}$ & $331 \mathrm{~W}$ & $471 \mathrm{~W}$ & $644 \mathrm{~W}$ & $856 \mathrm{~W}$ \\
Difference $(\%)$ & $-0.89 \%$ & $-0.89 \%$ & $-0.84 \%$ & $-0.92 \%$ & $-0.92 \%$
\end{tabular}

Fig. 10 also allows the analysis of the proposed method under wind speed transients. It is observed in Fig. 10(b) that the captured power difference between the sensor and ripple-based cases is also negligible during transients. The average power difference collected in the whole transient (time $6 \mathrm{~s}$ to $32 \mathrm{~s}$ ) is $-0.09 \mathrm{~W}$. However, the comparison between the sensor and model-based cases shows an increased power difference during the turbine acceleration, this difference being reversed during deceleration. This is explained by the actual and estimated turbine speed seen in Fig. 10(c) for the model-based case. Due to the speed error using model-based estimation, the turbine is operated at a speed higher than the optimal value. This results in increased kinetic energy stored in the turbine inertia, which is released during deceleration. Nevertheless, the average power collected in the whole transient is $2.8 \mathrm{~W}(0.64 \%)$ larger in case of sensor operation, slightly lower than for steady-state (see Table IV). 


\section{EXPERIMENTAL RESULTS}

Experimental results using the proposed method are presented in this section. The power converter using the topology in Fig. 1 is shown in Fig. 11. Control is implemented in a Texas Instrument TMS320F28335 microcontroller. Control sampling period and switching frequency of the boost converter are set to $20 \mathrm{kHz}$. H-bridge inverter switching frequency is $10 \mathrm{kHz}$. An Alxion 190STK3M generator is used. The wind turbine is emulated by a vector-controlled induction machine drive. Turbine inertia is emulated using the method described in [10]. The load drive includes an incremental encoder, which will be used to assess the accuracy of the proposed method. Main parameters of the system are shown in Tables I, II and III.

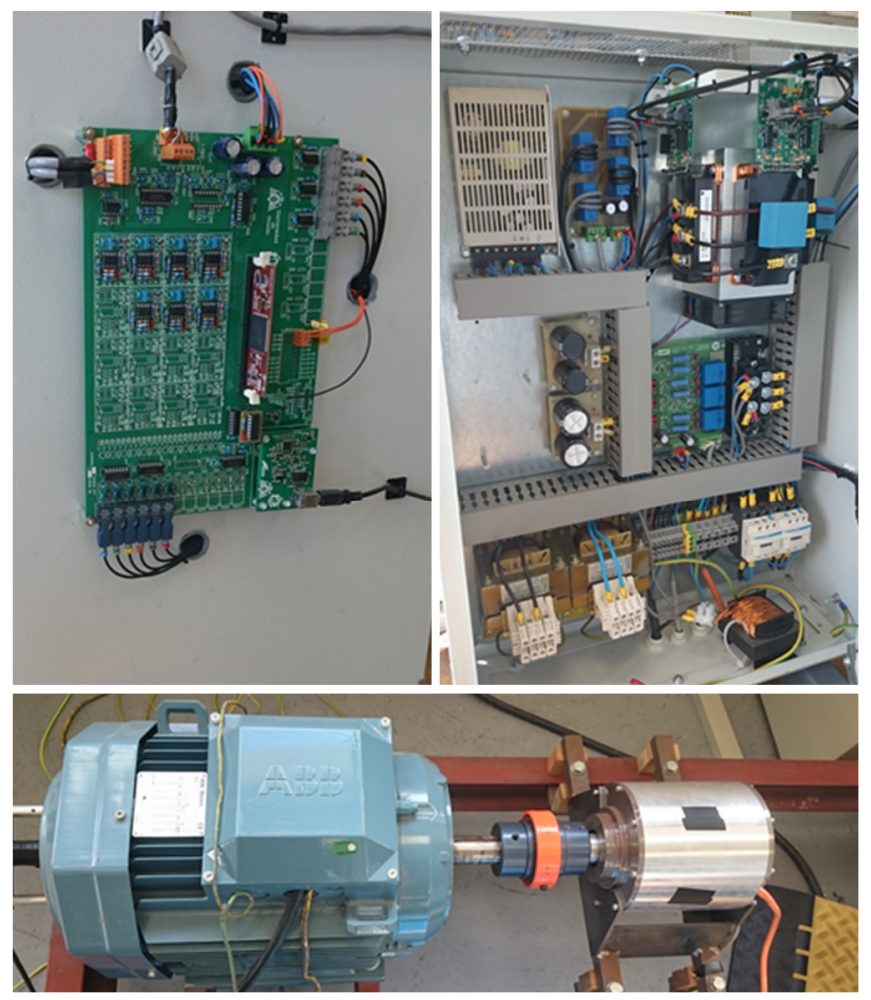

Fig. 11. Experimental setup. Top: control board (left) and power converter (right). Bottom: load motor (left) and permanent magnet synchronous generator (right)

The performance of the different signal processing stages seen in Fig. 3 is shown in Fig. 12. Unless otherwise stated, the rotor speed is controlled by the load drive. Rectifier voltage $v_{r}$ [Fig. 12(a)] is band-pass filtered to provide the voltage ripple $\tilde{v}_{r}$ [Fig. 12(b)], from which normalized voltage ripple complex vector components $v_{r n}=v_{r_{-} \alpha}$ and $v_{r_{-} \beta}$ are obtained [Fig. 12(c)]. These signals feed the PLL tracking the ripple frequency. Both the estimated rotor speed provided by the PLL $\hat{\omega}_{r m}^{P L L}$ and the actual speed are shown in Fig. 12(d). $\hat{\omega}_{r m}^{P L L}$ is low-pass filtered to obtain the speed estimate [Fig. 12(e)] used by the controller.

Fig. 13 shows the actual and estimated speed and the estimation error for three different current levels in the boost converter. The error is seen to decrease as the boost converter current increase, due to the larger magnitude 

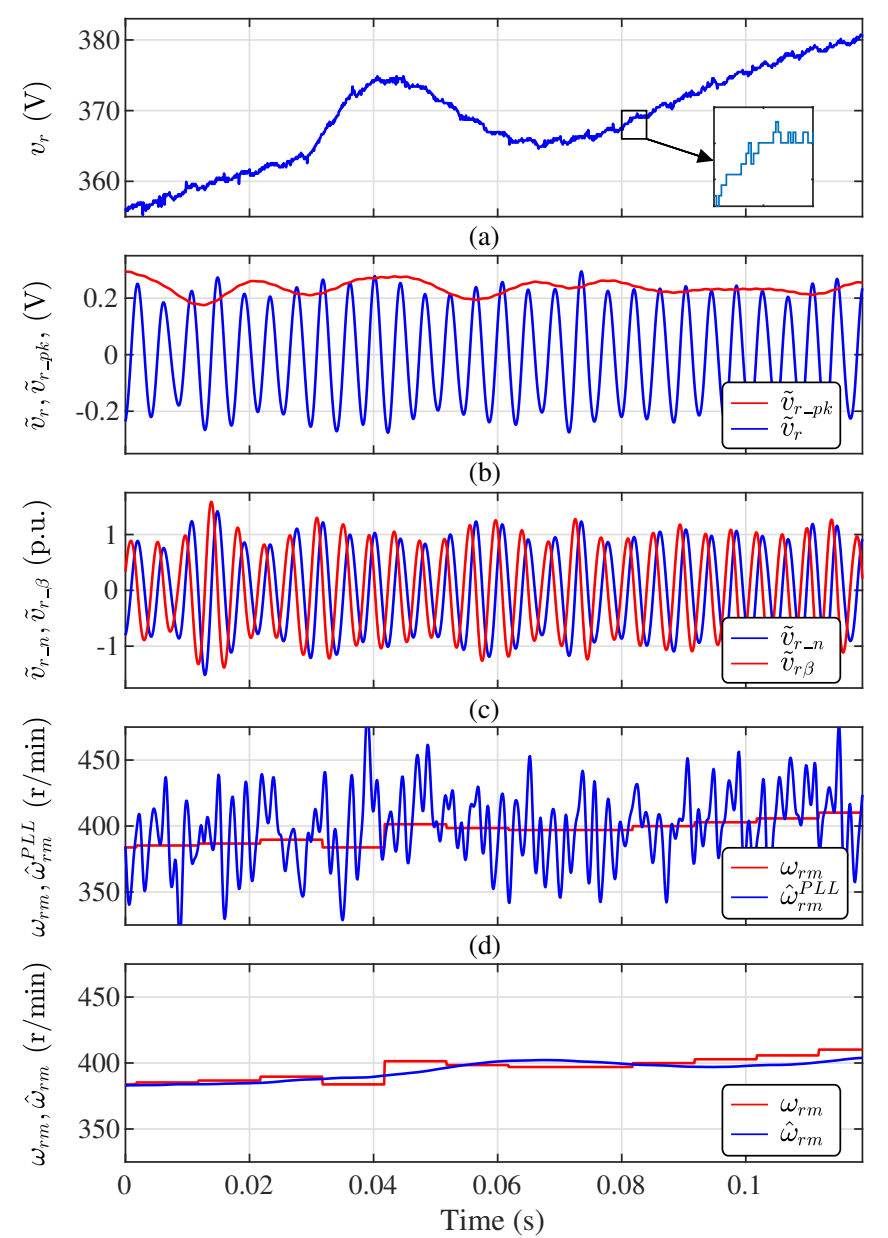

(e)

Fig. 12. Experimental results. (a) Rectifier voltage, $v_{r}$; (b) Voltage ripple $\tilde{v}_{r}$, and voltage ripple amplitude $\tilde{v}_{r_{-} p k}$; (c) Normalized components of voltage ripple complex vector $\tilde{v}_{r \alpha}$ and $\tilde{v}_{r \beta}$; (d) Unfiltered rotor speed estimation, $\hat{\omega}_{r m}^{n f}$, and actual rotor speed, $\omega_{r m}$; e) Rotor speed estimation $\hat{\omega}_{r m}$ and actual rotor speed, $\omega_{r m}$. Boost converter operated with a constant current $i_{b}=2.1 \mathrm{~A}$.

of the voltage ripple.

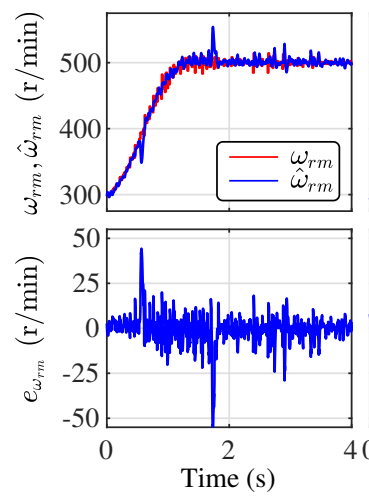

(a)

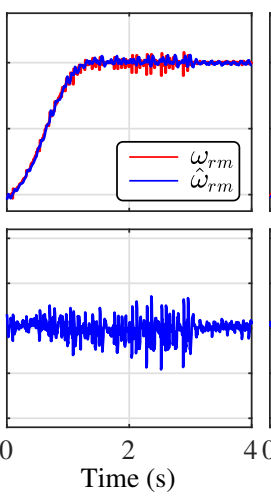

(b)
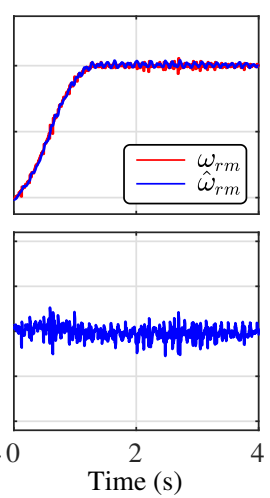

(c)

Fig. 13. Experimental results. Speed estimation during speed transients at constant boost current of (a) $i_{b}=0 \mathrm{~A}$; (b) $i_{b}=0.1 \mathrm{~A}$; (c) $i_{b}=3.7 \mathrm{~A}$. Top: Actual and estimated rotor speed, $\omega_{r m}$ and $\hat{\omega}_{r m}$. Bottom: Estimation error.

Fig. 14 shows the actual and estimated speed and the estimation error when step-like changes in the boost current occur with constant rotor speed. A large transient error is observed. This is due to the fast rectifier voltage 
variation [see Fig. 14(d)], which produces a distortion of the voltage ripple. It is noted however that this type of step-like changes is not expected in the wind turbine system, due to both the wind speed dynamics and the moderate bandwidth of the speed control loop.
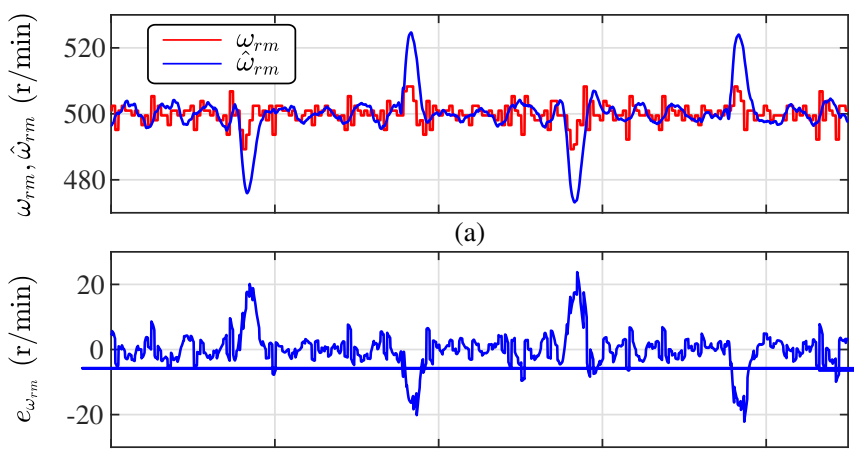

Fig. 14. Experimental results. Speed estimation performance during boost current transients at constant rotor speed. (a) Actual and estimated rotor speed, $\omega_{r m}$ and $\hat{\omega}_{r m}$ respectively; (b) Estimation error, $e_{\omega_{r m}}$; (c) Boost current, $i_{b}$; (d) Rectifier voltage, $v_{r}$.

To confirm the robustness of the proposed estimation method against temperature variations, the experiment in Fig. 13 was repeated at three different generator temperatures. Case temperature is measured using a thermocouple. The generator is operated at 2 A boost current. Test results can be seen in Fig. 15. No variation is observed in the estimation error due to temperature. It is interesting to note however in Fig. 15(c) the temperature impact on voltage magnitude.

Experimental results in Fig. 16 correspond to the simulation conditions shown in Fig. 5. Rotor speed is controlled by the generator while the load drive emulates the wind turbine behavior, including inertia [10]. Small errors in the estimated speed and turbine torque are observed in Fig. 16(a) and 16(b). The main difference between experimental and simulation results is the ripple seen in Fig. 16(a,b). This is due to the low bandwidth of the inertia emulator, which is not able to provide enough damping for the high-frequency components of torque ripple injected by both the load drive and generator. Despite this, the proposed method is seen to work as predicted by simulations. The speed estimate mean and standard errors are $0 \mathrm{r} / \mathrm{min}(0 \%)$ and $7.04 \mathrm{r} / \mathrm{min}(1.7 \%)$ respectively in the whole operating range seen in Fig. 16. The turbine torque estimate shows $0.18 \mathrm{Nm}(.8 \%)$ mean error and $3.71 \mathrm{Nm}(10 \%)$ standard 


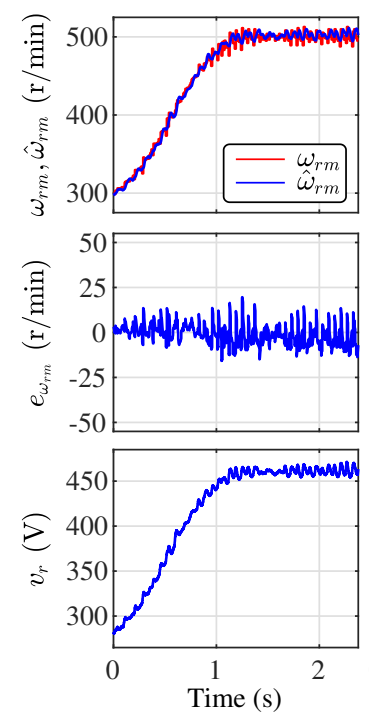

(a)
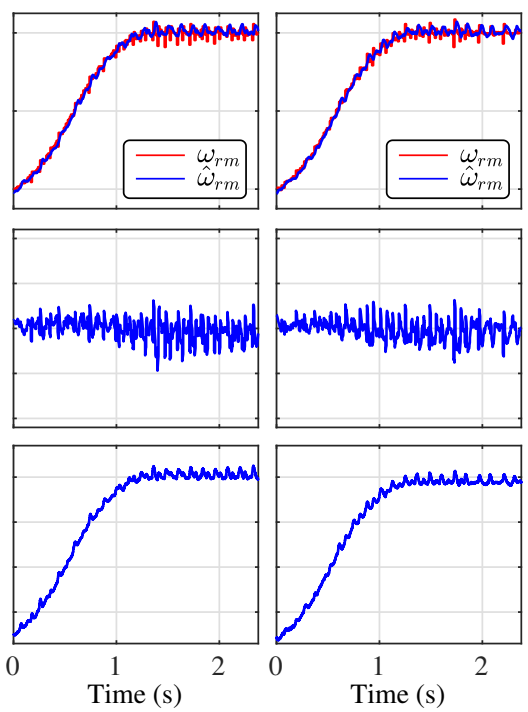

(b)

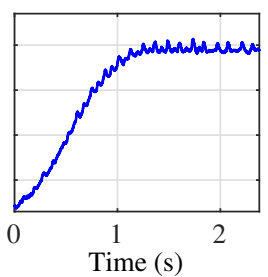

(c)

Fig. 15. Experimental results. Speed estimation during speed transients at constant boost current $i_{b}=2 \mathrm{~A}$ for a motor case temperature of (a) $T_{\text {case }}=20^{\circ} \mathrm{C}$; (b) $T_{\text {case }}=40^{\circ} \mathrm{C}$; (c) $T_{\text {case }}=60^{\circ}$. Top: Actual and estimated rotor speed, $\omega_{r m}$ and $\hat{\omega}_{r m}$ respectively. Middle: Estimation error, $e_{\omega_{r m}}$. Bottom: rectifier voltage, $v_{r}$.

error. It must be noted that the torque estimate is tracking ripple content that is being accounted as error when compared with the turbine torque commanded to the load drive inertia emulator.

\section{Vi. CONCLusions}

Most of the small power wind turbines use a diode rectifier followed by a boost converter in the machine side. A method to estimate the rotor speed from the rectifier output voltage ripple has been analyzed in this paper. Contrary to existing model-based speed estimation methods, the proposed method is insensitive to parameter variations, what improves both generator efficiency and the accuracy of high wind speed protection, due to the higher accuracy in the estimation of the turbine torque. It is finally noted that the combined use of model- and ripple-based methods could be used to estimate the electrical generator temperature; this is a topic of ongoing research. Simulation and experimental results confirm the feasibility of the proposed technique.

\section{REFERENCES}

[1] P. Gipe, Wind Power: Renewable Energy for Home, Farm, and Business, 2nd Edition. Chelsea Green Publishing, Apr. 2004.

[2] T. R. De Freitas, P. J. Menegz, and D. S. Simonetti, "Converter topologies for permanent magnetic synchronous generator on wind energy conversion system," in Power Electronics Conference (COBEP), 2011 Brazilian. IEEE, 2011, pp. 936-942. [Online]. Available: http://ieeexplore.ieee.org/xpls/abs_all.jsp?arnumber=6085292

[3] A. Sokolovs and L. Grigans, "Front-end converter choice considerations for PMSG-based micro-wind turbines," in 2015 56th International Scientific Conference on Power and Electrical Engineering of Riga Technical University (RTUCON), Oct. 2015, pp. $1-6$. 

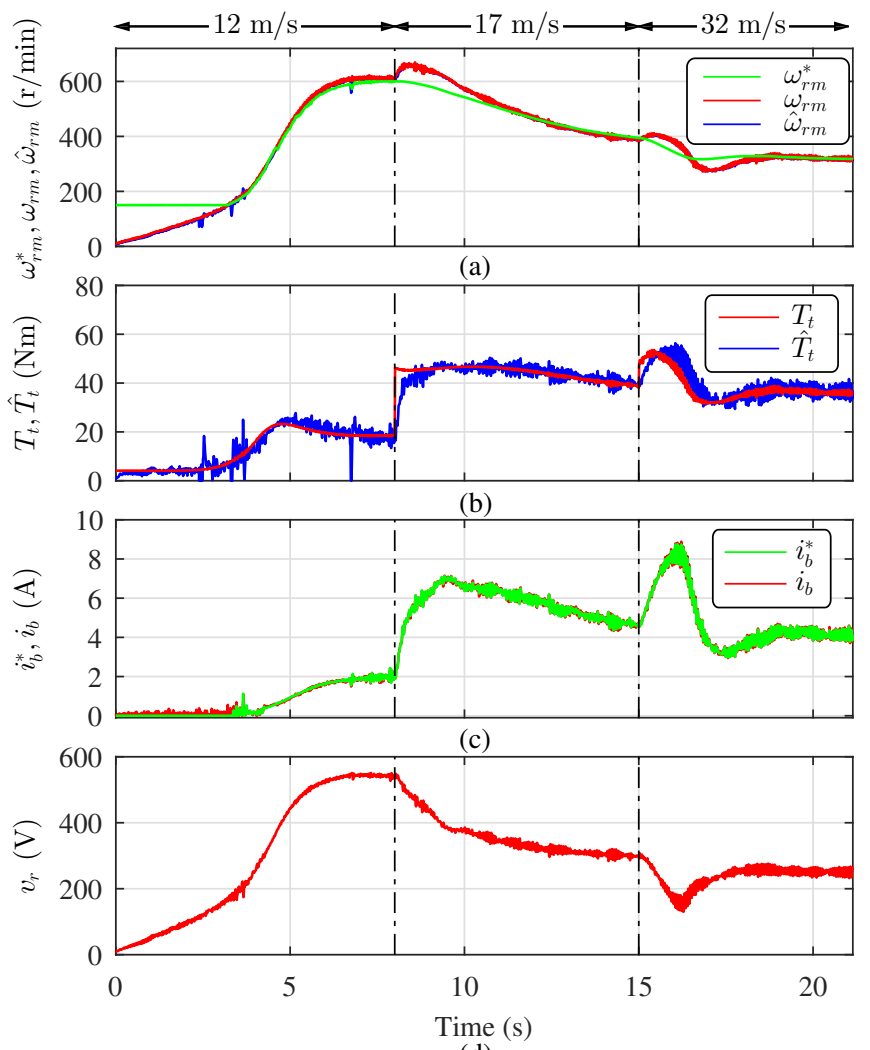

(d)

Fig. 16. Experimental results. Speed control and turbine torque estimation performance using the proposed method with increasing wind conditions $(12 \mathrm{~m} / \mathrm{s}, 17 \mathrm{~m} / \mathrm{s}$ and $32 \mathrm{~m} / \mathrm{s})$ : (a) Rotor speed command, $\omega_{r m}^{*}$, rotor speed, $\omega_{r m}$, and estimated rotor speed, $\hat{\omega}_{r m}$; (b) Turbine torque, $T_{t}$, and estimated turbine torque, $\hat{T}_{t} ;$ (c) Boost current command, $i_{b}^{*}$, and boost current, $i_{b}$; (d) Rectifier voltage, $v_{r}$. The load drive emulates the turbine behavior including turbine inertia.

[4] Z. Chen, X. Xiao, H. Wang, and M. Liu, "Analysis of converter topological structure for direct-drive wind power system with PMSG," in 2010 International Conference on Power System Technology (POWERCON). IEEE, Oct. 2010, pp. 1-5.

[5] J. Hui, A. Bakhshai, and P. Jain, "A Sensorless Adaptive Maximum Power Point Extraction Method With Voltage Feedback Control for Small Wind Turbines in Off-Grid Applications," IEEE Journal of Emerging and Selected Topics in Power Electronics, vol. 3, no. 3, pp. 817-828, Sep. 2015.

[6] _ _ "An Energy Management Scheme with Power Limit Capability and an Adaptive Maximum Power Point Tracking for Small Standalone PMSG Wind Energy Systems,” IEEE Transactions on Power Electronics, vol. PP, no. 99, pp. 1-1, 2015.

[7] Z. Dalala, Z. Zahid, and J.-S. Lai, "New overall control strategy for wind energy conversion systems in MPPT and stall regions," in 2013 IEEE Energy Conversion Congress and Exposition (ECCE), Sep. 2013, pp. 2412-2419.

[8] Y. Xia, K. Ahmed, and B. Williams, "A New Maximum Power Point Tracking Technique for Permanent Magnet Synchronous Generator Based Wind Energy Conversion System,” IEEE Transactions on Power Electronics, vol. 26, no. 12, pp. 3609-3620, Dec. 2011.

[9] J. Chen, J. Chen, and C. Gong, "New Overall Power Control Strategy for Variable-Speed Fixed-Pitch Wind Turbines Within the Whole Wind Velocity Range," IEEE Transactions on Industrial Electronics, vol. 60, no. 7, pp. 2652-2660, Jul. 2013.

[10] J. M. Guerrero, C. Lumbreras, D. D. Reigosa, P. Garcia, and F. Briz, "Control and Emulation of Small Wind Turbines Using Torque Estimators," IEEE Transactions on Industry Applications, vol. 53, no. 5, pp. 4863-4876, Sep. 2017.

[11] A. Ahmed, L. Ran, and J. Bumby, "New Constant Electrical Power Soft-Stalling Control for Small-Scale VAWTs," IEEE Transactions on Energy Conversion, vol. 25, no. 4, pp. 1152-1161, Dec. 2010.

[12] C. Lumbreras, J. M. Guerrero, P. Garca, F. Briz, and D. D. Reigosa, "Control of a Small Wind Turbine in the High Wind Speed 
Region," IEEE Transactions on Power Electronics, vol. 31, no. 10, pp. 6980-6991, Oct. 2016.

[13] Y. Y. Xia, J. E. Fletcher, S. J. Finney, K. H. Ahmed, and B. W. Williams, "Torque ripple analysis and reduction for wind energy conversion systems using uncontrolled rectifier and boost converter," IET Renewable Power Generation, vol. 5, no. 5, pp. 377-386, Sep. 2011.

[14] Y. Matsui, A. Sugawara, S. Sato, T. Takeda, and K. Ogura, "Braking Circuit of Small Wind Turbine Using NTC Thermistor under Natural Wind Condition,' in Power Electronics and Drive Systems, 2007. PEDS '07. 7th International Conference on, Nov. 2007, pp. $910-915$.

[15] J. Senanayaka, H. Karimi, and K. Robbersmyr, "Sliding-mode observer based sensor-less control of a small wind energy conversion system," in 2015 International Workshop on Recent Advances in Sliding Modes (RASM), Apr. 2015, pp. 1-6.

[16] A. Knight and G. Peters, "Simple wind energy controller for an expanded operating range," IEEE Transactions on Energy Conversion, vol. 20, no. 2, pp. 459-466, Jun. 2005.

[17] J. M. Guerrero, D. Reigosa, C. Blanco, F. Briz, and C. Lumbreras, "Sensorless speed control of a small wind turbine using the rectifier voltage ripple," in 2016 IEEE Energy Conversion Congress and Exposition (ECCE), Sep. 2016, pp. 1-8.

[18] M. Hinkkanen and J. Luomi, "Induction Motor Drives Equipped With Diode Rectifier and Small DC-Link Capacitance," IEEE Transactions on Industrial Electronics, vol. 55, no. 1, pp. 312-320, Jan. 2008. 